\title{
Cisplatin-induced apoptosis in human promyelocytic leukemia cells
}

\author{
MAURIZIO PREVIATI ${ }^{1,3}$, IRENE LANZONI $^{3}$, ELISA CORBACELLA ${ }^{3}$, SARA MAGOSSO $^{3}$, \\ VALERIA GUARAN $^{3}$, ALESSANDRO MARTINI ${ }^{2,3}$ and SILVANO CAPITANI ${ }^{1,3}$ \\ Departments of ${ }^{1}$ Morphology and Embryology, Human Anatomy Division, \\ ${ }^{2}$ Audiology, Ferrara University; and ${ }^{3}$ Center of Bioacustic, Ferrara University, Italy
}

Received February 16, 2006; Accepted April 17, 2006

\begin{abstract}
Cis-diamminedichloroplatinum (II) cisplatin (CDDP) is an organometallic compound frequently used in anti-cancer therapy, in particular ovarian, testicular, and head and neck tumors. We found cisplatin was effective against human promyelocytic leukemia cell line HL-60, inhibiting cell cycle progression and inducing time- and concentrationdependent cell death. Presence of nuclear fragmentation, caspase-3 cleavage and annexin $\mathrm{V}$ positivity suggests cell death occurred by apoptosis, although DNA internucleosomal fragmentation was not detected. In addition, analysis of malondialdehyde (MDA) production and protein carbonylation indicated that cisplatin increased lipid peroxidation and oxidation of cell proteins. This occurrence was prevented by antioxidants such as $\mathrm{N}$-acetylcysteine $(\mathrm{N}-\mathrm{aC})$ and glutathione (GSH), which, consistently, were also able to prevent CDDPinduced cell death. Collectively, these findings indicate that, besides growth inhibition, an increase of oxygen radicals and lipid degradation can account for a significant part of CDDPinduced apoptosis.
\end{abstract}

\section{Introduction}

Cisplatin, a potent inducer of growth arrest and/or apoptosis in most cell types has been used clinically for decades against a variety of human malignancies, including ovarian, testicular, bladder, head and neck, esophageal, and small cell lung cancers. Unfortunately, CDDP effects are not restricted to replicating cancer cells, but on the contrary it induces in vivo several adverse drug reactions, including renal, peripheral sensory and autonomic nervous system toxicity. In these

Correspondence to: Dr Maurizio Previati, Department of Morphology and Embryology, University of Ferrara, Via Fossato di Mortara 66, 44100 Ferrara, Italy

E-mail: prm@unife.it

Key words: cisplatin, reactive oxygen species, HL-60, protein carbonylation, apoptosis, nuclear fragmentation systems not only replicating but also non-dividing cells, such as hair cells (HC) and neurons, suffer for cisplatin action, suggesting that a relevant part of its toxicity is mediated by other mechanisms than by merely blocking cell replication.

This is consistent with the emerging point of view that the mechanism of action of an antineoplastic drug not only gives increasing importance to the antiproliferative effect, but also considers relevant the apoptosis inducing potential, as a way to restore a cancer-induced apoptotic deficiency. Effectively, in addition to DNA platination, different triggers were proposed to induce cisplatin cytotoxicity, such as oxidative stress or activation of specific intracellular pathways mediating the action of membrane receptors $(1,2)$; the importance of these factors is highlighted by the fact that their modulation allows for the control of cisplatin-dependent apoptosis. It has been shown that increased tolerance to DNA damage as well as antioxidant administration or altered expression of key proteins in signal transduction can increase resistance to cisplatin (3-7).

In the present study we examined the mechanism of action of CDDP on human promyelocytic leukemia cells. Our goal is to evaluate the relevance of CDDP-induced oxidative stress in the induction of apoptosis. With this aim, we investigated several morphological and biochemical apoptotic hallmarks (8), including phosphatidyl serine (PS) exposure on cell surface, activation of one or more proteases of the caspase family, DNA condensation and fragmentation at the nucleosomal level, cell shrinkage and formation of apoptotic bodies in the presence of an intact cell membrane. Subsequently, we quantified lipid degradation and protein oxidation and the extent of antioxidant efficacy in preventing both cell death and reactive oxygen species (ROS) production.

\section{Materials and methods}

Materials. Propidium iodide (PI), GSH, N-aC, and all other common laboratory reagents were obtained from Sigma Chemical Co (St. Louis, MO, USA). The source of CDDP was Platinex from Bristol-Myers Squibb. Dulbecco's Modified Eagle Medium (DMEM), fetal calf serum (FCS) and RPMI1640 were from Gibco, BRL (Grand Island, NY, USA).

Cell culture. The HL-60 cell line, obtained from the American Type Culture Collection (Rockville, MD, USA), was routinely 
Table I. Effect of CDDP on the cell cycle.

\begin{tabular}{lcc}
\hline & NT & $50 \mu$ M CDDP \\
\hline G0/G1 & 55.7 & 77.6 \\
S & 15.2 & 4.3 \\
G2/M & 30.1 & 18.1 \\
\hline
\end{tabular}

HL-60 cells, untreated or treated with $50 \mu \mathrm{M}$ CDDP for $24 \mathrm{~h}$, were fixed with $70 \%$ ethanol, labelled with PI and the amount of cell DNA ( $2 \mathrm{~N}, 4 \mathrm{~N}$ or intermediate amounts) was evaluated by flow cytometry. Data indicate the percentage over 10,000 events of cells in the indicated phase of cell cycle.

Table II. PS exposure after CDDP treatment.

\begin{tabular}{|c|c|c|c|}
\hline & $\mathrm{AnnV}^{-}, \mathrm{PI}^{-}$ & $\mathrm{AnnV}^{+}, \mathrm{PI}^{-}$ & $\mathrm{AnnV}^{+}, \mathrm{PI}^{+}$ \\
\hline NT & 86 & 8 & 4 \\
\hline CDDP $50 \mu \mathrm{M} \quad 5 \mathrm{~h}$ & 78 & 10.5 & 8.5 \\
\hline CDDP $100 \mu \mathrm{M} \quad 5 \mathrm{~h}$ & 28 & 17.5 & 38 \\
\hline CDDP $50 \mu \mathrm{M} 24 \mathrm{~h}$ & 4 & 45 & 50.5 \\
\hline CDDP $100 \mu \mathrm{M} 24 \mathrm{~h}$ & 8 & 33.5 & 57.5 \\
\hline
\end{tabular}

Livng cells were labeled with annexin V-FITC, which stains in green cells exposing PS, and $2 \mu \mathrm{g} / \mathrm{ml} \mathrm{PI}$, which stains in red cells undergoing membrane damages. Data represent the percentage over 10,000 events of cellls showing no fluorescence $\left(\mathrm{AnnV}^{-}, \mathrm{PI}^{-}\right)$, only green fluorescence $\left(\mathrm{AnnV}^{+}, \mathrm{PI}^{-}\right)$, or green and red fluorescence $\left(\mathrm{AnnV}^{+}, \mathrm{PI}^{+}\right)$.

maintained in RPMI-1640 (Gibco) supplemented with $10 \%$ FCS at a density ranging from 0.3 to $1.5 \times 10^{6}$ cells $/ \mathrm{ml}$.

Viability assay. For all the experiments, cells were resuspended at the density of $0.6-1 \times 10^{6}$ cells $/ \mathrm{ml}$ in fresh medium and challenged with vehicle, CDDP or a combination of CDDP and other drugs. Cell viability was determined by a PI exclusion assay. Briefly, at the end of the incubation period PI at a final concentration of $50 \mu \mathrm{g} / \mathrm{ml}$ was added, the samples were allowed to stand for $15 \mathrm{~min}$ at room temperature and then analyzed by flow cytometry (FACStar Becton Dickinson, St. Josè, CA, USA) (9). Untreated cells were used to identify the PI-low population, while for the PI-bright population, HL-60 cells were permeabilised by adding Nonidet P40 ( $0.05 \%$ final concentration) and then stained with PI and analyzed.

Cell cycle analysis. HL-60, untreated or treated with $50 \mu \mathrm{M}$ CDDP for $24 \mathrm{~h}$, were collected by centrifugation, washed with phosphate buffered saline (PBS) twice and fixed with $70 \%$ ethanol on ice for $30 \mathrm{~min}$, washed again twice with PBS, and incubated for $30 \mathrm{~min}$ at $37^{\circ} \mathrm{C}$ in presence of $10 \mu \mathrm{g} / \mathrm{ml}$ RNase, DNase-free and $50 \mu \mathrm{g} / \mathrm{ml}$ PI. Samples were successively analyzed by flow cytometry and data were evaluated with CellFIT software (Becton Dickinson).

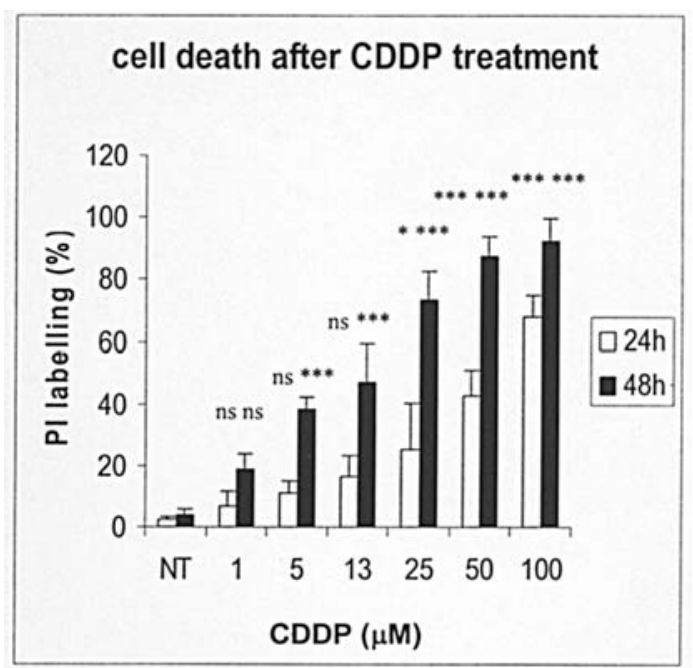

Figure 1 . Cell viability after cisplatin treatment. Living HL-60 cells were collected after 24 or $48 \mathrm{~h}$ of treatment with CDDP at the indicated concentrations, immediately supravitally stained with $50 \mu \mathrm{g} / \mathrm{ml} \mathrm{PI}$, and analyzed by flow cytometry. Each data point represents the percentage over 10,000 events of cells which show a PI fluorescence intensity typical of strongly damaged/dead cells, and is the mean of three experiments performed in triplicate.

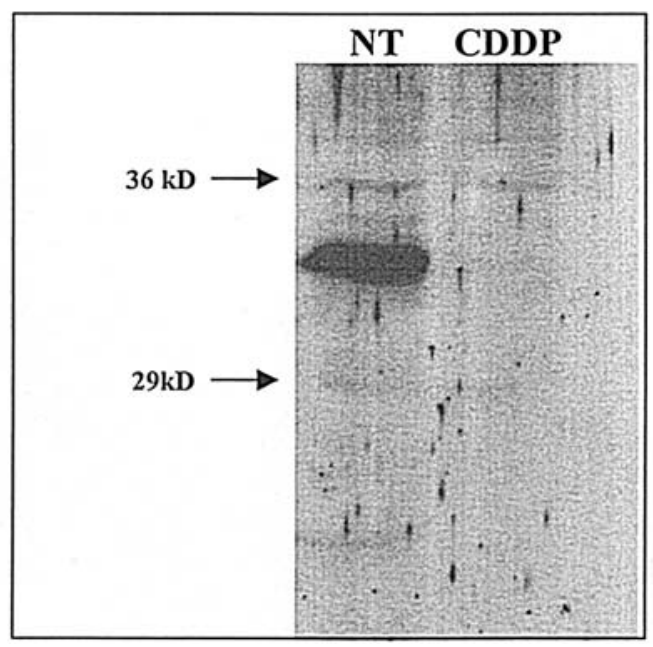

Figure 2. Proteolytic caspase degradation. HL-60 cells were treated with $10 \mu \mathrm{M}$ CDDP for $24 \mathrm{~h}$, and then cell proteins were separated by SDSPAGE, electroblotted on nitrocellulose and immuno-revealed for caspase-3.

Annexin $V$ assay. Annexin $\mathrm{V}$ assay was performed using the human annexin V-FITC kit from Bender MedSystems (Burlingame, CA).

In situ immunocytochemistry. After treatment, HL-60 were collected by spinning in a cyto spin over a cover slip, washed twice with PBS and then fixed with $4 \%$ paraformaldehyde for $30 \mathrm{~min}$ at room temperature. Fixed cells were washed with PBS and stained with $2 \mu \mathrm{g} / \mathrm{ml}$ 4,6-diamidino-2-phenylindole (DAPI, Sigma), which selectively stains DNA and allows for the evaluation of nuclear morphology. Slides were mounted with DABCO glycerol and examined under a fluorescence microscope equipped with the appropriate filters (Nikon Eclipse TE 2000-U, Nikitalia, Italy). 
A
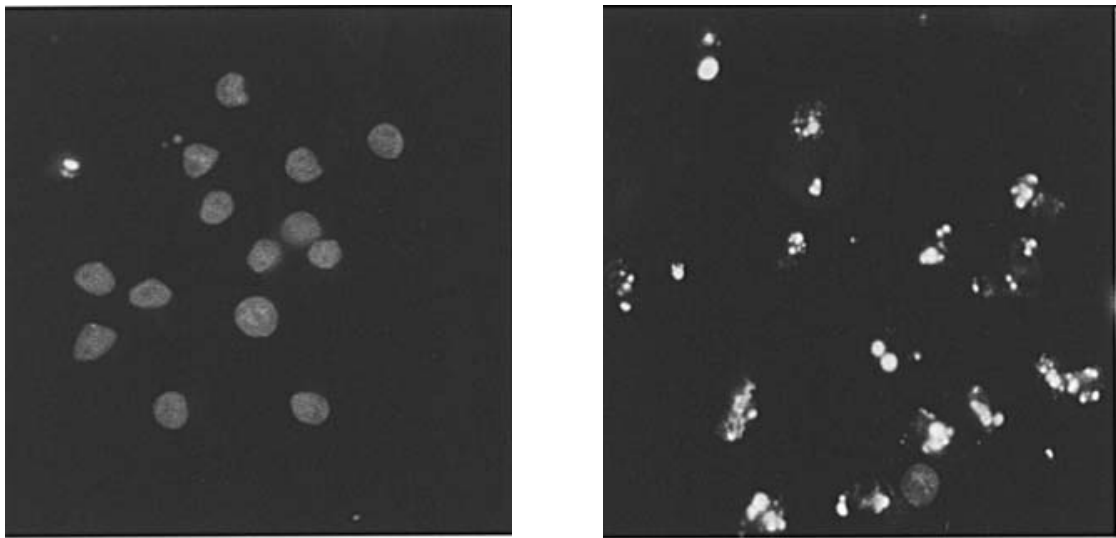

NT

$\mathrm{CPT} 10 \mu \mathrm{M}$

B

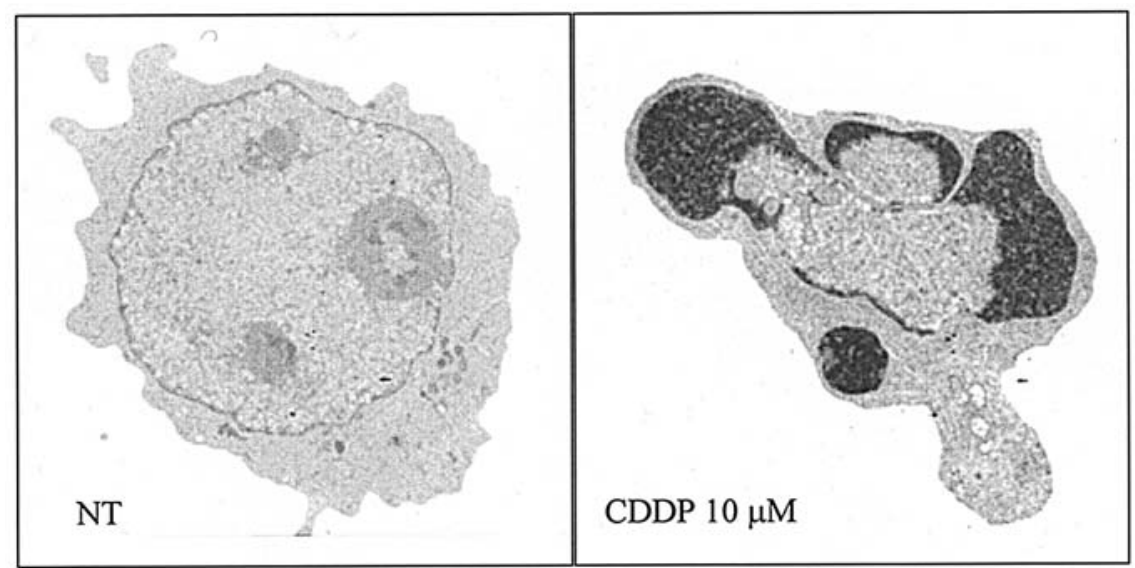

Figure 3. Effects of CDDP on nuclear morphology. Nuclear morphology was investigated using fluorescent microscopy and DAPI staining, which reveal extensive nuclear fragmentation after $10 \mu \mathrm{M}$ CDDP for $24 \mathrm{~h}(\mathrm{~A})$, and transmission electron microscopy, which shows chromatin compaction and nuclear blebbing after $24 \mathrm{~h}$ in the presence of $10 \mu \mathrm{M}$ CDDP (B).

Caspase-3 analysis. Western blot analysis of caspase cleavage was carried out as described previously (10).

DNA analysis. HL-60 cells were treated with different CDDP concentrations for $24 \mathrm{~h}$. Genomic and fragmented DNA was extracted using phenol/chloroform partitioning, analyzed by migration on an agarose gel $(2 \%)$ at $100 \mathrm{~V}$, and visualized with ethidium bromide staining. As molecular weight markers we used a mix of $\lambda$ HindIII (Fermentas) and $100 \mathrm{bp}$ (Invitrogen).

Protein determination. Protein concentration was determined using the bicinchoninic acid assay (BCA), and a $2 \mathrm{mg} / \mathrm{ml}$ bovine serum albumin (BSA) solution as standard (Pierce, Rockford, IL) (11).

Evaluation of malondialdehyde (MDA) formation and protein carbonylation products. MDA was assayed as previously reported (9). Spectrophotometric assay of protein carbonylation products was performed according to a previous report (12), on samples containing 10-20 $\mu \mathrm{g}$ of protein. Data are presented as the mean \pm SD of four replicate samples from at least three separate experiments.

Statistical analysis. Statistical analyzes were performed using the Kruscal-Wallis test, followed by a multiple comparison test. A p-value of $<0.05$ was considered significant.

\section{Results}

After CDDP challenge, HL-60 cells ceased in cycle progression: cells accumulated at the G1 checkpoint, with an increase of the number of cells in $\mathrm{G} 0 / \mathrm{G} 1$ phase up to $77.6 \%$, and a parallel reduction of cells present in S and G2/M phase (Table I). A significant increase in cell toxicity was associated to this stop, as revealed by a viability assay based on PI exclusion. The assay discriminates between viable cells, which can actively extrude PI and are only fairly fluorescent, and damaged or dead cells, which are brightly fluorescent. When we challanged HL-60 cells with increasing concentrations of CDDP for 24 or $48 \mathrm{~h}$, we found a highly significant increase in PI labelling, which indicates a time and concentration dependent drop in membrane integrity (Fig. 1).

Additionally, we found that this indicator of cell death was preceded by more specific and typical hallmarks of apoptosis. Positive labelling with annexin $\mathrm{V}$, which indicated a flipping of phosphatidylserine (PS) from the internal to the external leaflet of cell membrane, occurred after $5 \mathrm{~h}$ of treatment and was CDDP concentration-dependent (Table II). In particular, we found the flipping of PS occurred also in the absence of PI staining (Table II, $\mathrm{AnnV}^{+}$, $\mathrm{PI}^{-}$cells). This indicates that the apoptotic marker appeared before the onset of the loss of membrane integrity, and consequently does not represent an 


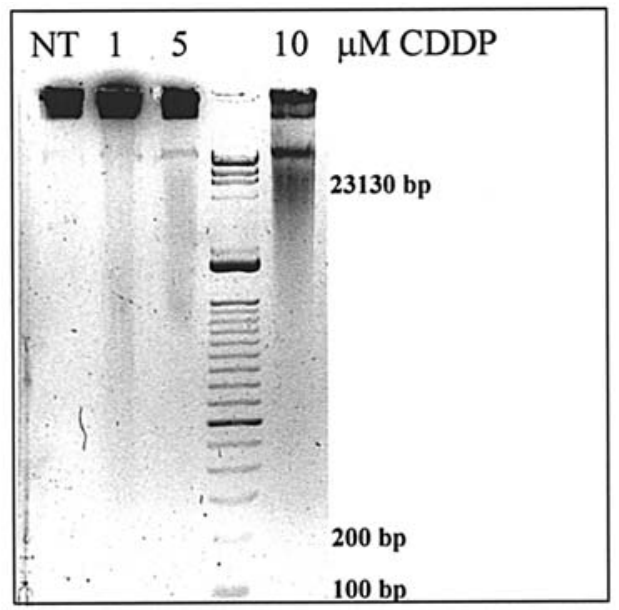

Figure 4. Analysis of DNA fragmentation. After $24 \mathrm{~h}$ in the presence of increasing CDDP concentrations, DNA was extracted by liquid/liquid partitioning with a phenol/chloroform mixture, precipitated and migrated on an agarose gel. While no clear internucleosomal fragmentation pattern (ladder) was present, a concentration-dependent aspecific DNA degradation was detectable, with recovery of high molecular weight DNA fragments.

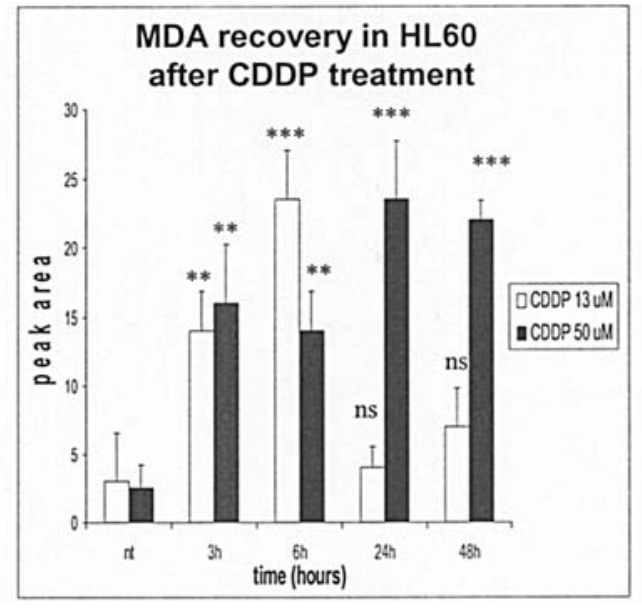

Figure 6. HPLC quantification of MDA. After treatment for the indicated times at 13 and $50 \mu \mathrm{M}$ CDDP, cells were lysed and lysates reacted with 2thiobarbituric acid and further analyzed by HPLC. Data are expressed as MDA peak area, normalized for an equal amount of cells. MDA peak was unambiguosly identified by spiking samples with MDA standard (9). Statistical significance was found for the untreated sample (nt) at the same time point.

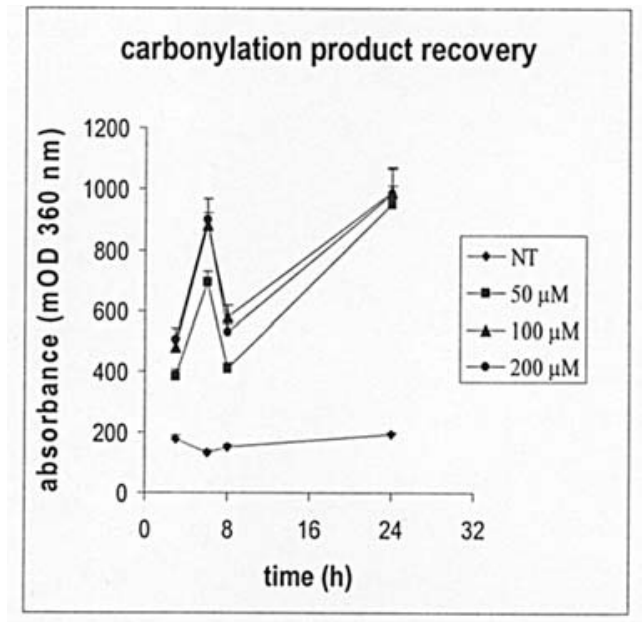

Figure 5. Protein carbonylation products. After $24 \mathrm{~h}$ in the presence of increasing CDDP concentrations, cell proteins were precipitated and labelled with 2,4-dinitrophenylhydrazine, which specifically stains carbonyl compounds. Data are expressed as absorbance in $\mathrm{mOD}$ at $360 \mathrm{~nm}$, and are all significantly different from non-treated samples at the same time point $(\mathrm{p}<0.001)$.

artifact due to an undesired staining of intracellular membranes, but can be regarded as an actual early indicator of programmed cell death.

Further confirmation of a prevalence of a programmed cell death path as a primary response to low CDDP concentrations come from the analysis of caspase degradation. We observed at $24 \mathrm{~h}$ after $50 \mu \mathrm{M}$ CDDP treatment the complete disappearance of caspase-3 band (Fig. 2).

In addition, DAPI staining followed by visual inspection of nuclear morphology under fluorescence microscopy revealed that the cell nuclei underwent deep active changes, fragmenting into several small condensed micronuclei (Fig. 3A). Transmission electron microscopy (TEM) revealed the presence of cell blebbing, and deep rearrangements of nuclear structure. We observed compaction and margination of chromatin inside nuclear blebs, a preliminary

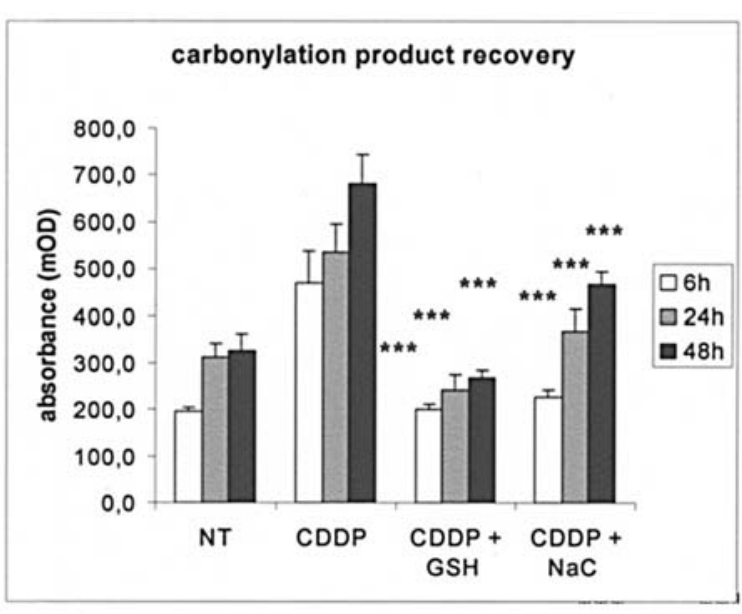

Figure 7. Recovery of protein carbonylation products after CDDP and antioxidant cotreatment. HL-60 cells were treated for 6,24 or $48 \mathrm{~h}$ in the presence of $50 \mu \mathrm{M}$ CDDP or CDDP plus $1 \mathrm{mM} \mathrm{GSH}$ or $1 \mathrm{mM} \mathrm{N}-\mathrm{aC}$. Data represent the absorbance at $360 \mathrm{~nm}$, in $\mathrm{mOD}$, normalised to an equal number of cells. Statistical significance was found for the cisplatin-treated sample at the same time point.

step for nuclear fragmentation into apoptotic bodies. These phenomena occurred in the presence of an intact cell membrane (Fig. 3B).

On the other hand, we did not find occurrence of internucleosomal fragmentation, which is another typical hallmark of apoptosis. When we separated HL-60 DNA on agarose gel electrophoresis, we observed that CDDP-treated samples failed to generate internucleosomal DNA fragments, showing instead a continuous pattern of DNA fragments apparently starting from $30 \mathrm{~kb}$ (Fig. 4). Appearance of DNA fragments depended upon CDDP concentrations, being maximal at $10 \mu \mathrm{M}$, while at higher CDDP concentration all the fragmented DNA was completely lost from the cells after $24 \mathrm{~h}$ of incubation (data not shown).

To further characterize the molecular events which prompt CDDP-induced cell death, we used an assay of protein 


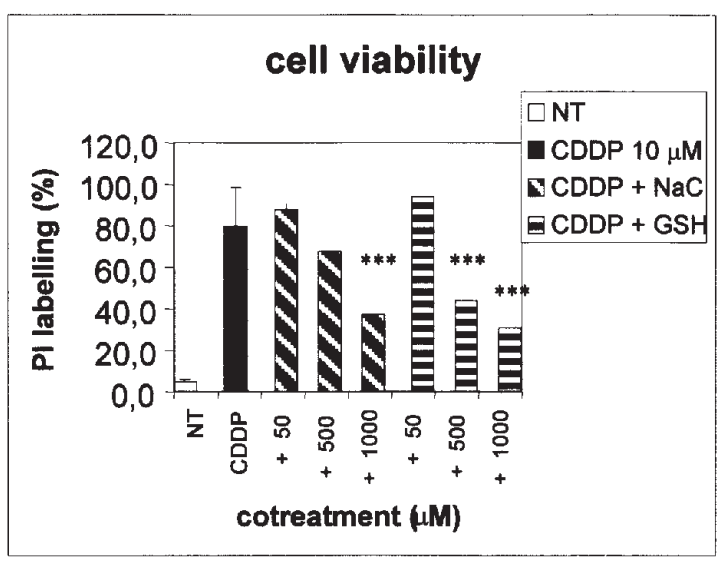

Figure 8. Cell viability after CDDP and antioxidant cotreatment. HL-60 were treated with $10 \mu \mathrm{M}$ CDDP or CDDP plus different concentrations of GSH and $\mathrm{N}-\mathrm{aC}$, supravitally stained with $50 \mu \mathrm{g} / \mathrm{ml} \mathrm{PI}$, and analyzed by flow cytometry. Each data point represents the percentage over 10,000 events of cells which show a PI fluorescence intensity typical of strongly damaged/ dead cells, and is the mean of two experiments performed in triplicate. Statistical significance was found for the cisplatin-treated sample.

peroxidation to indirectly evaluate the involvement of ROS. This assay measures the amount of carbonyl groups bound to the cell proteins. We found, after CDDP treatment, an increase in protein carbonylation recovery. The increase was detectable from $3 \mathrm{~h}$ of cisplatin treatment, significantly peaked at $6 \mathrm{~h}$ with a decrease at $10 \mathrm{~h}$, to rise again, and it was time- and CDDP concentration-dependent (Fig. 5).

Protein carbonylation is an indicator not only by direct oxygen insertion but also by addition of lipid-deriving aldehydes (13). We tested the hypothesis of lipid peroxidation and breakdown burst by setting a thiobarbituric acid (TBA)based HPLC assay and quantifying MDA. MDA is an aldehyde-bearing molecule partially responsible for the elevation of carbonylation products, and was expected to increase in a time shorter than the carbonylation products. Consistently, MDA showed a peak at $3 \mathrm{~h}$ after platinum challenge (Fig. 6).

The importance of an oxidative step in CDDP-induced cell death was further strengthened by the use of antioxidants such as $\mathrm{N}-\mathrm{aC}$ and GSH. These compounds were able not only to revert protein carbonylation (Fig. 7), but overall to significantly reduce the extent of cell death (Fig. 8), strongly supporting the possibility for a pivotal role of ROS in the CDDP-induced apoptosis.

\section{Discussion}

Cisplatin is a chemotherapeutic molecule believed to exert its toxic activity both through necrosis and apoptosis. In HL-60 we demonstrate its ability to induce a time and concentration dependent cell death, which, in the low micromolar range of toxicity (below $100 \mu \mathrm{M} \mathrm{CDDP}$ ), occurs by apoptosis. Actually, we can detect several coordinated events, like as caspase proteolysis, membrane exposure of PS, which occurred also in absence of other membrane damages, and deep nuclear changes. These included nuclear blebbing and fragmentation, together with chromatin compaction and margination inside nuclear blebs. Additionally, cell DNA was cleaved into both high and low molecular weight fragments in a CDDP concentration-dependent manner, probably through an aspecific nuclease activity.

Cisplatin can elicits its cytotoxic effect using several different routes: genotoxicity is perhaps the best characterized, but not unique or the most relevant in the exploitation of antitumor activity. Cisplatin is able to react with functional residues of proteins and low-molecular weight molecules (14). In this way it gives rise to a wide number of different platination products, affects in the same time multiple cellular functions and intracellular pathways, and suggests the antineoplastic activity can derive from the interaction of several cytotoxic activities. In the present study, we note that its dose- and time-dependent toxicity can be related at least to two different mechanisms. Cisplatin was able to block cell cycle progression, a finding consistent with its reported capacity to originate inter- and intrastrand cross links, and ultimately to interfere with binding and action of transcription factors and other members of the replicative machinery.

In addition to the genotoxic activity, a second relevant route can be detected. We observed CDDP significantly increases the amount of reactive aldehydes. Several lipid peroxides such as hydroperoxyeicosatetraenoic acids (HPETEs), alkenals and hydroxy alkenals, including HNE and MDA, are formed during physiological events or oxidative bursts (15). These endogenous aldehydes can react with cellular proteins introducing a carbonylic group exposed on the protein surface, giving rise to an increase of carbonylation products.

In CDDP-treated HL-60, the increase of free aldehydes and bound carbonylic groups occurred both in a biphasic fashion. We detected at 3 and $6 \mathrm{~h}$ after treatment a significant increase of MDA and carboxylation products; both decreased at a later time, to rise again at 24-48 h, during the onset of cell death. While the late increase of aldehydes and carbonylation products can simply indicate the occurrence of necrotic postapoptotic oxidation of the lipidic and proteic compartment, the first peak of aldehydes and carbonylation products, which appeared soon after CDDP challenge, indicates the presence of a significant early oxidative damage of cell membranes and proteins. These events are known to trigger cell death $(16,17)$.

Consistently with the hypothesis of a triggering role for oxidative events we found that $\mathrm{N}-\mathrm{aC}$ and GSH not only were able to completely prevent protein carbonylation, but they significantly although not completely prevent cell death. Antioxidants suppress the peak of aldehydes and carbonylation products occurring at 3-6 h, and eliminate in a concentrationdependent manner a significant part of cisplatin-induced cell death, leaving probably only the genotoxic-induced death. The fact that extracellular GSH is not a cell permeant does not affect its capacity to increase intracellular reducing power. It can be extracellularly cleaved and the resulting amino acids can be internalized and used in GSH resynthesis.

These findings, together with the fact that cisplatin can decrease the intracellular GSH concentration (18), allowing for a intracellular burst of oxidative events, suggest that part of toxic action of cisplatin is due to an increase of intracellular ROS. 
In conclusion, our study proves the ability of CDDP to induce a time- and dose-concentration-dependent apoptosis, highlighting the ability of GSH and $\mathrm{N}-\mathrm{aC}$ to suppress CDDPdependent peroxidation of lipids and carbonylation of proteins. This prevents part of of CDDP-induced cell death and prompts the hypothesis of involvement of ROS in cisplatin-induced apoptosis, suggesting that lipid and protein oxidation products can be an early marker of this event.

\section{Acknowledgements}

The present study was supported by grants from CNR (Progetto Finalizzato Biotecnologie) and from MURST (COFIN 2002 to M. Previati, and COFIN 2001 to S. Capitani) as well as from the University of Ferrara $(60 \%$ funds, first and second level) to S. Capitani and A. Martini. $\mathrm{V}$. Guaran and S. Magosso are recipient of a $\mathrm{PhD}$ in Biomedical, Endocrinological and Neurophysiological Sciences. I. Lanzoni, E. Corbacella and S. Magosso were recipient of grants from the European Community Project QLG3-CT-2002-01463 BIOEAR: http://www.uta.fi/ projektit/eubioear/. S. Magosso was recipient of a grant from Fondazione Cassa di Risparmio di Cento, http://www. fondazionecrcento.it/.

\section{References}

1. Zanke BW, Boudreau K, Rubie E, Winnett E, Tibbles LA, Zon L, Kyriakis J, Liu FF and Woodgett JR: The stress-activated protein kinase pathway mediates cell death following injury induced by cis-platinum, UV irradiation or heat. Curr Biol 6: 606-613, 1996.

2. Chen Z, Seimiya H, Naito M, Mashima T, Kizaki A, Dan S, Imaizumi M, Ichijo $\mathrm{H}$, Miyazono, $\mathrm{K}$ and Tsuruo T: ASK1 mediates apoptotic cell death induced by genotoxic stress. Oncogene 18: 173-180, 1999.

3. Fink D, Zheng H, Nebel S, et al: In vitro and in vivo resistance to cisplatin in cells that have lost DNA mismatch repair. Cancer Res 15: 1841-1845, 1997.

4. Lanzi C, Perego P, Supino R, Romanelli S, Pensa T, Carenini N, Viano I, Colangelo D, Leone R, Apostoli P, Cassinelli G, Gambetta RA and Zunino F: Decreased drug accumulation and increased tolerance to DNA damage in tumor cells with a low level of cisplatin resistance. Biochem Pharmacol 15: 1247-1254, 1998.
5. Gabaizadeh R, Staecker H, Liu W and Van De Water TR: BDNF protection of auditory neurons from cisplatin involves changes in intracellular levels of both reactive oxygen species and glutathione. Mol Brain Res 50: 71-78, 1998.

6. Perez RP: Cellular and molecular determinants of cisplatin resistence. Eur J Cancer 34: 1535-1544, 1998.

7. Mase H, Sasaki A, Alcade RE, Nakayama S and Matsumura T: Regulation of apoptosis reduction in the cisplatin-resistent A431 cell line by Bcl-2 and CPP32. Chemotherapy 46: 67-76, 2000.

8. Majno $G$ and Joris I: Apoptosis, oncosis, and necrosis. An overview of cell death. Am J Pathol 46: 3-15, 1995.

9. Previati M, Lanzoni I, Corbacella E, et al: RNA expression induced by cisplatin in an organ of corti-derived immortalized cell line. Hear Res 196: 8-18, 2004.

10. Bertolaso L, Gibellini D, Secchiero P, et al: Accumulation of catalitically active PKC- $\zeta$ into the nucleus of HL50 cell line plays a key role in the induction of granulocyte differentiation mediated by all-trans retinoic acid. Br J Haematol 100: 541-549, 1998.

11. Smith PK, Krohn RI, Hermanson GT, et al: Measurement of protein using bicinchoninic acid. Anal Biochem 150: 76-85, 1985.

12. Levine RL, Williams JA, Stadtman ER and Shacter E: Carbonyl assays for determination of oxidatively modified proteins. Methods Enzymol 233: 346-357, 1994.

13. Berlett BS and Stadtman ER: Protein oxidation in aging, disease, and oxidative stress. J Biol Chem 272: 20313-20316, 1997.

14. Pascoe JM and Roberts JJ: Interactions between mammalian cell DNA and inorganic platinum compounds. I. DNA interstrand cross-linking and cytotoxic properties of platinum (II) compounds. Biochem Pharmacol 23: 1359-1365, 1974.

15. Kontos HA and Hess ML: Oxygen radicals and vascular damage. Adv Exp Med Biol 161: 365-375, 1983.

16. Dalle Donne I, Giustarini D, Colombo R, Rossi R and Milzani A: Protein carbonylation in human diseases. Trends Mol Med 9: 169-176, 2003.

17. Byoung JS, Yunjo S, Myung AB, Jae-Eun P, Jie W and KyuShik J: Apoptosis of PC12 cells by 4-hydroxy-2-nonenal is mediated through selective activation of the c-Jun N-Terminal protein kinase pathway. Chem Biol Interact 130-132: 943-954, 2001.

18. Goto S, Yoshida K, Morikawa T, Urata Y, Suzuki K and Kondo T: Augmentation of transport for cisplatin-glutathione adduct in cisplatin-resistant cancer cells. Cancer Res 55: 4297-4301, 1995. 